Informatorium voor Voeding en Diëtetiek 
Majorie Former • Gerdie van Asseldonk Jacqueline Drenth • Gerdien Ligthart-Melis (Redactie)

\section{Informatorium voor Voeding en Diëtetiek}

Dieetleer en Voedingsleer Supplement 95 - april 2017

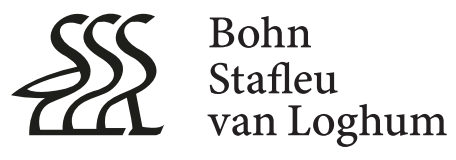


Redactie

Majorie Former

Almere, The Netherlands

Gerdie van Asseldonk

Delft, The Netherlands
Jacqueline Drenth

Garrelsweer, The Netherlands

Gerdien Ligthart-Melis

Almere, The Netherlands

ISBN 978-90-368-1773-8

ISBN 978-90-368-1774-5 (eBook)

DOI 10.1007/978-90-368-1774-5

(C) Bohn Stafleu van Loghum, onderdeel van Springer Media B.V. 2017

Alle rechten voorbehouden. Niets uit deze uitgave mag worden verveelvoudigd, opgeslagen in een geautomatiseerd gegevensbestand, of openbaar gemaakt, in enige vorm of op enige wijze, hetzij elektronisch, mechanisch, door fotokopieën of opnamen, hetzij op enige andere manier, zonder voorafgaande schriftelijke toestemming van de uitgever.

Voor zover het maken van kopieën uit deze uitgave is toegestaan op grond van artikel 16b Auteurswet $\mathrm{j}^{\circ}$ het Besluit van 20 juni 1974, Stb. 351, zoals gewijzigd bij het Besluit van 23 augustus 1985, Stb. 471 en artikel 17 Auteurswet, dient men de daarvoor wettelijk verschuldigde vergoedingen te voldoen aan de Stichting Reprorecht (Postbus 3060, 2130 KB Hoofddorp). Voor het overnemen van (een) gedeelte(n) uit deze uitgave in bloemlezingen, readers en andere compilatiewerken (artikel 16 Auteurswet) dient men zich tot de uitgever te wenden.

Samensteller(s) en uitgever zijn zich volledig bewust van hun taak een betrouwbare uitgave te verzorgen. Niettemin kunnen zij geen aansprakelijkheid aanvaarden voor drukfouten en andere onjuistheden die eventueel in deze uitgave voorkomen, De uitgever blijft onpartijdig met betrekking tot juridische aanspraken op geografische aanwijzingen en gebiedsbeschrijvingen in de gepubliceerde landkaarten en institutionele adressen.

NUR 893

Basisontwerp omslag: Studio Bassa, Culemborg

Automatische opmaak: Scientific Publishing Services (P) Ltd., Chennai, India

Bohn Stafleu van Loghum

Het Spoor 2

Postbus 246

3990 GA Houten

www.bsl.nl 


\section{Voorwoord bij supplement 95}

\section{April 2017}

Beste collega,

In het eerste supplement van 2017 treft u twee nieuwe onderwerpen aan die zeer interessant zijn voor de dagelijkse praktijk van de diëtist:

- 'Dieetbehandeling eosinofiele oesofagitis', geschreven door mw. W. Frank, diëtist in het Gelre ziekenhuis Apeldoorn.

Eosinofiele oesofagitis is een chronisch ontstoken slokdarm met een verhoogd aantal eosinofielen (witte bloedcellen). Dit ziektebeeld wordt in toenemende mate gediagnosticeerd. De ontsteking gaat gepaard met oedemen, ringen en groeven in de mucosa van de slokdarm. Diagnose en behandeling bestaan onder andere uit het lokaal toedienen van corticosteroïden en/of een elementair dieet of eliminatiedieet. In Nederland (en Europa) bestaat nog geen eenduidige behandeling. Diëtisten hebben kennis nodig van het dieet bij een voedselovergevoeligheid en werken nauw samen met (kinder-)MDL-artsen en (kinder)allergologen.

- 'Gepersonaliseerde voeding en zelfmonitoring', geschreven door mw. M. Former-Boon, diëtist, hoofdredacteur Informatorium voor Voeding \& Diëtetiek, Almere, dr. ir. A. Ronteltap, senior onderzoeker Lectoraat Crossmediale Communicatie in het Publieke Domein (PubLab), Hogeschool Utrecht, en ir. B.D.S. Clabbers, Senior Business Developer Personalized Nutrition \& Health, TNO, Zeist.

In de nieuwe definitie voor gezondheid wordt gezondheid omschreven als het dynamische vermogen van mensen om zich met veerkracht aan veranderende omstandigheden aan te passen. Hierin past het zelf regie voeren en zelfmanagement. Met gezondheidstools zijn lichaamsfuncties, zoals bloeddruk, hartslag, bloedglucosespiegel, zuurstofsaturatie, cognitieve prestaties en welbevinden te meten. Gepersonaliseerde voeding en leefstijladviezen sluiten hierbij aan. Voor bedrijven biedt dit de mogelijkheid om op het individu afgestemde producten en diensten te ontwikkelen. Diëtisten (en andere professionals) kunnen met behulp 
van innovaties op het gebied van zelfmonitoring persoonlijke gegevens verzamelen om de individuele behandeling af te stemmen. Gepersonaliseerde interventies zijn mogelijk effectiever en kunnen de compliance verhogen.

De volgende hoofdstukken zijn geactualiseerd:

- 'Eetgedrag van ouderen: regulatie van voedselinname' door S.J.G.M. van der Staak, MSc, en R.M.A.J. Ruijschop, PhD, beiden werkzaam bij NIZO food research.

- 'Voeding bij kinderen met oncologische aandoeningen' door dr. M.D. van de Wetering, kinderoncoloog, en drs. M.E. Dijsselhof, diëtist kindergeneeskunde/ klinisch epidemioloog, beiden werkzaam in het Emma Kinderziekenhuis/AMC, Amsterdam.

- 'Voeding bij neuromusculaire aandoeningen' door mw. J.C. Wijnen, diëtist, verbonden aan Vereniging Spierziekten Nederland.

\section{Tot slot}

Mw. dr. Gerdien Ligthart-Melis heeft met ingang van 1 januari haar functie als redactielid opgezegd. Caroelien Schuurman, diëtist en onderzoeksmedewerker aan de Hogeschool Amsterdam, heeft haar plaats ingenomen.

Met vriendelijke groet, namens de redactie, Majorie Former-Boon, hoofdredacteur Informatorium voor Voeding en Diëtetiek 


\section{Inhoud}

Hoofdstuk 1 Dieetbehandeling eosinofiele oesofagitis $\ldots \ldots \ldots \ldots \ldots$. 1

W. Frank

$1.1 \quad$ Inleiding. . . . . . . . . . . . . . . . . . . 1

1.2 Prevalentie ......................... 2

1.3 Symptomen ........................... 2

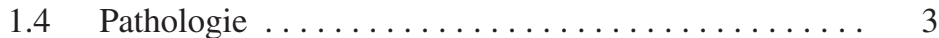

1.5 Diagnostiek ......................... 6

1.6 Behandeling . . . . . . . . 6

1.7 Voorwaarden voor dieettherapieën. . . . . . . . . 10

1.8 Herintroductie . . . . . . . . . . . . . . . . . . . . . 11

1.9 Rol van de diëtist . . . . . . . . . . . . . . . 11

1.10 Besluit .......................... 14

Literatuur......................... 14

Hoofdstuk 2 Gepersonaliseerde voeding en zelfmonitoring . . . . . . . 17

M. Former, A. Ronteltap en B.D.S. Clabbers

$2.1 \quad$ Wat is gezondheid? .................. 17

2.2 De rol van voeding in het nieuwe begrip van gezondheid.......................... 19

2.3 Implementatie, privacy en veiligheid.......... 27

2.4 Rol van de diëtist . . . . . . . . . . . . . . . . . . . 29

2.5 Tot besluit....................... 30

Literatuur........................ 30

Hoofdstuk 3 Eetgedrag van ouderen: regulatie van voedselinname . . . 33

S.J.G.M. van der Staak en R.M.A.J. Ruijschop

$3.1 \quad$ Inleiding. ........................ 33

3.2 Oorzaken van verandering eetgedrag en voedselvoorkeur....................... 34 
3.3 Adviezen voor de praktijk .............. 39

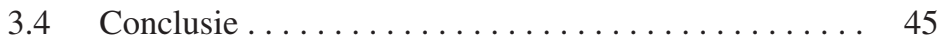

Literatuur. . . . . . . . . . . . . . . . . . . . . . 45

Hoofdstuk 4 Voeding bij kinderen met oncologische aandoeningen . . . 49

M.D. van de Wetering en M.E. Dijsselhof

$4.1 \quad$ Inleiding . . . . . . . . . . . . . . . . . 49

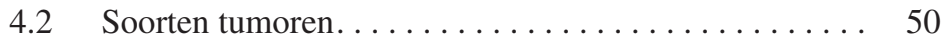

4.3 Behandelingen $\ldots \ldots \ldots \ldots \ldots \ldots \ldots \ldots \ldots \ldots \ldots$

4.4 Voedingsinterventies $\ldots \ldots \ldots \ldots \ldots \ldots \ldots \ldots \ldots \ldots$

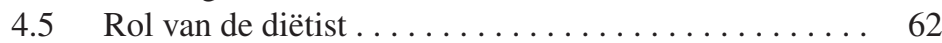

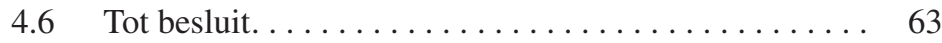

Literatuur......................... 64

Hoofdstuk 5 Voeding bij neuromusculaire aandoeningen. . . . . . . 65

J.C. Wijnen

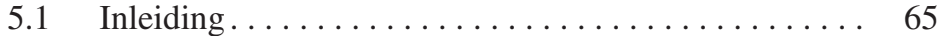

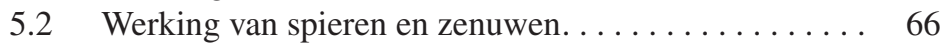

$5.3 \quad$ Spierziekten ................... 67

5.4 Voedingsgerelateerde problematiek en behandeling ... 75

5.5 Conclusie ......................... 93

Literatuur....................... 94 